\title{
O canto fúnebre em "o enterro das bonecas": oralidade e performance na literatura arrieteana
}

\author{
Edvaldo Nunes dos Santos ${ }^{(1)}$
}

(1) Aluno do curso de Letras da Universidade Estadual de Alagoas (UNEAL), Campus Arapiraca. E-mail: edvaldosanttos8@outlook.com

Resumo - Esta pesquisa analisa a intrínseca relação entre literatura oral e performance através da leitura de um dos doze contos da obra Maria Flor etc. (2002), da escritora Arriete Vilela, intitulado "o enterro das bonecas". A personagem principal da narrativa, de nome Esterlina, transita entre o presente e suas brincadeiras de infância, das quais, a de vestir mortalhas em bonecas e enterra-las, enquanto entoa cânticos. Dessa ritualística, ocorre o desdobramento em manifestações bem típicas da cultura popular, como de apelo aos santos católicos, vestir roxo, de cavar covas no chão e perfumar com flor de laranjeira. Outrossim, performatizando a partir de uma relação estética que advém da relação entre vocalidade, corpo e espaço, nos termos de Paul Zumthor (2007), que designa o ato performativo como uma ação, sempre em curso, que se assegura pelas sensações que provoca e é anterior à própria invenção da escrita; ou uma ação simbólica, pela visão interpretativista de Geertz (2008) e que percebemos como reflexo da identidade de um povo e que, por ser sempre fronteiriça, de acordo com o antropólogo Stuart Hall (2008), só pode ser interpretada de forma cituada, como parte de um emaranhado cultural, sobre o qual, age e resulta.

Palavras-chave: Cânticos; Literatura oral; O enterro das bonecas; Performance.

\section{The funeral song in "the burial of dolls": literature, orality and performance in the literature}

\begin{abstract}
This research analyzes the intrinsic relationship between oral literature and performance by reading one of the twelve short stories of the work Maria Flor etc. (2002), by the writer Arriete Vilela, entitled "the burial of dolls". The main character of the narrative, named Esterlina, transits between the present and his childhood games, of which, to wear shrouds in dolls and bury them, while singing songs. Of this ritualistic, there is the unfolding in manifestations very typical of popular culture, such as appeal to Catholic saints, wearing purple, digging pits on the ground and perfume with orange blossom. Moreover, performing from an aesthetic relationship that comes from the relationship between vocality, body and space, in the terms of Paul Zumthor (2007), who designates
\end{abstract}


Ano 6, Vol. 6 (2), no 2. 2021, julho/dezembro de 2021.

https://doi.org/10.48179/revext.v6i2.299

the performative act as an action, always in progress, which is ensured by the sensations it provokes and is prior to the very invention of writing; or a symbolic action, by the interpretative view of Geertz (2008) and which we perceive as a reflection of the identity of a people and that, because it is always borderline, according to anthropologist Stuart Hall (2008), can only be interpreted in a exclusive way, as part of a cultural tangle, on which it acts and results.

Keywords: Performance; Oral literature; Songs; The burial of the dolls.

\section{INTRODUÇÃO}

Segundo o Dicionário informal ${ }^{1}$ caracterizamos, de forma geral, as incelenças ou excelências como "cantigas de guarda, cantigas de sentinelas ou benditos de defuntos, constituem uma forma de expressão musical, típicas de localidades do Ceará, sertão nordestino, cidades do vale do Paraíba e, em escala menor, em outras regiões do Brasil". Estes cânticos compõem a grande costura que é a cultura popular sertaneja e tornam-se de suma importância na vivência religiosa local, já que, por meio da música, essas comunidades passam a comungar entre si e entrar em contato com o universo místico e simbólico.

No contexto literário, podemos dizer que o cantar aos mortos não é algo novo, sendo possível encontrar registros desde tempos antigos. Como sabe-se, houve uma série de poetas gregos e romanos que dedicaram sua poesia a construção de cantos aos falecidos. Os quais, recebiam o nome de Elegia e eram carregados de uma métrica bem típica, tendo como função principal serem declamados. Podemos citar o poeta Ovídio, como um desses grandes nomes.

Houve uma poesia cantada, muito antes da escrita, com a qual nos familiarizamos com o passar do tempo, esquecendo a primeira. Pois, ao recorrer à cultura oral para

1 Disponível em Incelença (dicionarioinformal.com.br) 
Ano 6, Vol. 6 (2), no 2. 2021, julho/dezembro de 2021.

https://doi.org/10.48179/revext.v6i2.299

construção de sua obra, Arriete nos brinda com uma seleção dessas narrativas, típicas da literatura popular, agora registradas a partir de seu texto. Materializando-as sobre a construção enigmática da personagem Esterlina, muda, guardiã do passado e em sua brincadeira favorita de enterrar bonecas com toda a rigorosidade do rito. Assim, ela promove diálogos com figuras míticas, como as carpideiras, mulheres que eram pagas para chorar durante os velórios, ou com as próprias beatas do sertão, que misturam sincreticamente as tradições e performatizam a partir de um catolicismo a sua maneira, onde a voz ocupa lugar de destaque, surgindo como ferramenta de entoação de textos orais que tem como finalidade a elevação do espírito do morto.

\section{PROCEDIMENTO METODOLÓGICO}

Se deu a partir de leitura da obra supracitada e fichamento. A busca por bibliografia que comporte as realizações estéticas presentes no texto literário da escritora alagoana Arriete Vilela, exigiu leituras teóricas acerca dos temas: cultura popular, performance, teoria da literatura e oralidade. Dos quais, fizemos um recorte, de acordo com a recorrência de temas como identidade e ritualização.

Por fim, o estudo comporta uma visão interpretativista, amparado em perspectivas críticas de análise dos processos simbólicos de representação dos ritos fúnebres, por meio de sua presença na fortuna crítica arrieteana, materializado nas chamadas incelenças. As quais, pudemos melhor identificar a partir da rememoração de conversas informais que tivemos desde a infância, já que, o canto é sempre presente no cotidiano sertanejo e pudemos frequentar velórios onde esse tipo de invocação se faz presente, seja para lembrar o falecido ou para encaminhar sua passagem ao além túmulo.

\section{RESULTADOS E DISCUSSÃO}

O conto "o enterro das bonecas", é o oitavo conto que constitui a obra Maria Flor etc. (2002), da escritora alagoana Arriete Vilela. Logo de início, somos confrontados com uma personagem inerte, sobre a qual, só sabemos as impressões que nos são passadas por um 
Ano 6, Vol. 6 (2), no 2. 2021, julho/dezembro de 2021.

https://doi.org/10.48179/revext.v6i2.299

narrador onisciente, que a desnuda a partir da falta que a mulher, de nome Esterlina, sente de um suposto pai que, ao chegar de viagem a presenteava com lindas bonecas. O pai não mais faz parte de sua vida, forçando-a a viver de reminiscências, ela passara então a não se importar mais com o presente, muda, imóvel, resgatando sua brincadeira predileta de quando menina.

\begin{abstract}
Há anos Esterlina não diz uma palavra. Fez-se silêncio para salvar-se como memória. $\mathrm{O}$ imediato não lhe interessa, mas o passado. Fora-se esvaziando pouco a pouco de todas as experiências adultas, sobretudo de marido e filhos, sempre tão barulhentos e em constantes festas alcoolizadas. Postara-se outra vez na infância, redescobrindo-se como mistério e surpresa. [..] Seu olhar aparentemente oco, desgarrado, ampara-se solene e calmo, em tempos outros, longínquos tempos, e resgata, em meio a tantas lembranças, a brincadeira predileta de quando menina: o enterro das bonecas. Esterlina possuía muitas e variadas bonecas. Ganhava-as do pai, que a mimava como se ela também fora uma boneca, porque ela era de fato bonita e graciosa. (VILELA, 2002, pg. 42)
\end{abstract}

O prazer que Esterlina encontrava em enfeitar e enterrar suas bonecas, ligava-a ao passado, ao mesmo tempo, tornam-se registros de práticas culturais. Mais à frente, a narrativa traz que a personagem, no trato com as bonecas, " recolhia duas ou três, corria à sala de costura e catava retalhos para as pequenas mortalhas. Usava cores variadas, caso não encontrasse a mais apropriada: a cor roxa" (Vilela, 2002. pg. 42-43). A escolha pelo roxo, típico das mortalhas, por exemplo, prova que o que temos na narrativa é o desdobramento de relações simbólicas, assim como se dá na vida sertaneja, a partir da ritualização e da evocação ao valor místico das cores, onde a cor passa a representar a tristeza e, por consequente, o luto . Só então, após vestir devidamente as bonecas novas, a personagem partia para o cortejo e funeral dessas.

Então, podemos perceber o valor performancial que se apresenta no conto, traduzido a partir de uma citação de Paul Zumthor (2007), que nos diz que "a performance não apenas se liga ao corpo mas, por ele, ao espaço. Esse laço se valoriza por uma noção, a de teatralidade" (pg. 39). A teatralidade, no sentido não de falsidade, mas de relação entre indivíduo e meio para culminar no ato performativo, pode ser vista na relação com as bonecas. Outra passagem que assegura o valor de performance na literatura arrieteana é quando a personagem Esterlina está para enterrar sua boneca e assim; 
Ano 6, Vol. 6 (2), n 2. 2021, julho/dezembro de 2021.

https://doi.org/10.48179/revext.v6i2.299

[...] Ela vivia os desdobramentos de um ritual: ia-se registrando como prazer ao cavar a terra, no quintal humoso de casa. Não tinha pressa. Ajeitava as bordas das pequenas covas, nas quais apergia gotas de água de flor de laranjeira, e atapetavalhes o fundo, forrando-o com folhas novas, verdíssimas de pitangueira. (VILELA, 2002, pg. 43)

O processo de ritualização, sobre o qual a mulher se coloca, carece dos símbolos para fazer-se completo e para tornar-se prenhe em seu significado: o cavar as covas, espirrar água de flor de laranjeira, vestir a cor roxa. Isso ocorre, porque para que a performance se efetive ela carece de "um contexto ao mesmo tempo cultural e situacional" (Zumthor, 2007, pg.31). A cultura dita que um velório precisa de determinadas indumentárias e certos ritos místicos devem ser guardados, logo, o caminho seguido por Esterlina é fruto de uma relação de identificação com valores identitários de seu povo; isso assegura que os ritos não caiam em esquecimento, ao mesmo tempo que constroem a grande teia do popular.

Seguindo o ritual, Esterlina arrumava as bonequinhas nas covas e então começava a entoar as incelenças que ouvira, ainda menina, enquanto frequentava velórios da sua região. De forma poética, a narrativa registra os cânticos que são oferecidos aos mortos, em uma maneira própria e, esses, partem da tradição oral sertaneja, são traços identitários que Esterlina guarda e performatiza, como maneira de reviver um passado só seu, que ao mesmo tempo, desnuda suas origens e sua relação com toda uma comunidade. Outrossim, ela canta;

$$
\begin{gathered}
\text { Lá vem uma alma² } \\
\text { Pisando no chão } \\
\text { Vai dizendo à outra } \\
\text { Ô que buracão! }
\end{gathered}
$$

Esse buracão

2 As incelenças são da tradição oral sertaneja, sendo manifestações de nossa cultura do sertão e parte da identidade de nosso povo. Esses textos orais são retomados pela autora, onde passam a enriquecer as narrativas de Arriete Vilela. 
Ano 6, Vol. 6 (2), no 2. 2021, julho/dezembro de 2021.

É a sepultura

https://doi.org/10.48179/revext.v6i2.299

Essa terra fria

É a cobertura.

Uma incelença

Que nos deu no paraíso

Adeus, irmã, adeus

Até o dia do juízo.

Os elementos que constituem o cântico são, por excelência, fúnebres: "uma alma"; "o chão"; "ô que buracão"; "sepultura"; "terra fria" e "cobertura". A vocalidade e o misticismo que são apresentados através do canto, acabam por confirmar a ideia de que seria um ritual que se segue, o qual, nomeamos como performance de literatura oral e é, esta manifestação, ponto de fusão entre o mundo simbólico e o mundo real. De acordo com o antropólogo Geertz (2008), esta é a essência de um rito, sendo que, "num ritual, o mundo vivido e o mundo imaginado fundem-se sob a mediação de um único conjunto de formas simbólicas” (pg. 82). Pois, tanto as vestes das bonecas, a água de cheiro de laranjeira e o cantar das incelenças, são estas maneiras do simbólico fazer-se presente no mundo real através do uso do corpo e de sua ligação a uma situação bem específica, que no caso seria a da morte e do embalsamento.

Nestes cânticos, os santos católicos também ocupam lugar de destaque. Sendo responsáveis por ajudar na elevação do espírito do falecido e reflexo da relação com o catolicismo contemporâneo pregado nas regiões rurais; onde os santos, alguns deles nem canonizados pela igreja- como é o caso de Padre Cícero-, ocupam lugar de destaque.

A presença mítico religiosa nessas localidades afastadas acaba por determinar a maneira de vida das pessoas que lá vivem; questões como plantio, colheita, o trato com as doenças, tudo fica restrito a uma presença mística, que também pode ser vista tanto na figura da rezadeira, da mesma maneira associada ao divino, quanto nas simpatias que são realizadas com objetivo do amor, acalmar tempestade e etc. Percebemos narrativa de Arriete Vilela, a presença de uma incelença que denota esta relação típica, onde as figuras religiosas são evocadas; 
Ano 6, Vol. 6 (2), no 2. 2021, julho/dezembro de 2021.

https://doi.org/10.48179/revext.v6i2.299

Meu Sinhô São Pedro
Chaveiro do Céu
Vós nos abra a porta
Que eu não sou herege.
Vós nos abra a porta
Amanhã bem cedo
Que eu quero ir pro céu
Mais Sinhô São Pedro.

Vós nos abra a porta

Pelo bom Jesus

Eu quero ir pro céu

Mais a Santa Cruz.

Vós nos abra a porta

Abra sem temor

Que eu quero ir pro céu

Mais Nosso Senhor.

Vós nos abra a porta

Abra sem demora

Que eu quero ir pro céu

Com Nossa Senhora.

A voz reminiscente de Esterlina se liga a voz de muitas mulheres do nordeste do Brasil. Em um processo de identificação, a performance encontra sua totalidade a partir da intrínseca relação que se apresenta entre corpo, voz, ambiente, situação e identidade cultural e tudo isso integra o conceito de teatralização, onde a figura das beatas cantoras aparece latente.

São Pedro, o santo chaveiro, é mencionado em sua função de abrir as portas do céu para o falecido. Posteriormente, são citados outros santos, como Nosso Senhor (Jesus 
Ano 6, Vol. 6 (2), no 2. 2021, julho/dezembro de 2021.

https://doi.org/10.48179/revext.v6i2.299

Cristo) e Nossa Senhora que, no imaginário popular religioso sertanejo, são de suma importância.

Percebemos que, somente na imagética do nordeste- dos santos, dos cânticos, da religião- é que faz-se validada a performance de Esterlina. Isso nos revela as zonas de fronteira que o próprio conceito de identidade cria, não sendo essa unitária, mas dependendo de um sistema próprio de identificação que, em suma, acaba se tornado ferramenta de manutenção dos costumes e de suas diferenciações. As identidades, por consequente, integram um sistema específico, que só pode ser compreendido a partir de seu lugar de formação. Segundo algumas correntes da antropologia;

É precisamente porque as identidades são construídas dentro e não fora do discurso que nós precisamos compreendê-las como produzidas em locais históricos e institucionais específicos, no interior de formações e práticas discursivas específicas, por estratégias e iniciativas específicas. Além disso, elas emergem no interior do jogo de modalidades específicas de poder e são, assim, mais o produto da diferença e da exclusão do que o signo de uma unidade idêntica (HALL, 2008, pg. 109).

A memória que se perpetua e salvaguarda a partir da performance idealizada pela personagem na obra, demonstra que somente em locais específicos a produção simbólica popular pode se manifestar. Como afirmam as pesquisas antropológicas na atualidade sobre o conceito de identidade; esses locais são também trincheiras, que servem para separar o que pertence a um grupo étnico e o que não encontra validação dentro de suas crenças, tudo situado sobre o preceito da identificação.

Por outro lado, os cantos fúnebres que são aqui apresentados não são somente manifestações artísticas ou objeto puramente de análise, eles são parte fundamental dentro de um sistema imagético nordestino, como qual partilhamos. Partem de uma relação com a comunidade, de uma vivência com o sagrado e seus desdobramentos e foram criados sob o pressuposto da existência da vida após a morte, da existência de um céu, amplamente difundido pela visão cristã.

Os corpos dos sertanejos, ao serem envolvidos pela mística do canto, tornam-se objeto de comunhão entre o mundo dos vivos e o mundo espiritual. O momento da oração, aqui em tom de canto, é um momento de respeito dentro da cultura do povo do sertão. 
Ano 6, Vol. 6 (2), no 2. 2021, julho/dezembro de 2021.

https://doi.org/10.48179/revext.v6i2.299

Mulheres costumavam rezar em latim, algumas rezas que ensinavam os velhos catecismos; ainda hoje podemos presenciar as senhoras mais velhas que percorrem distâncias pelos caminhos de terra batida, quando alguém morre, para rezar o terço e cantar em intenção ao finado.

Performam sobre o pressuposto de que os santos atendem quem tem fé e que a vida no mundo dos mortos continua, sendo muito boa para quem preservou seus costumes e muito má para quem esqueceu de vigiá-los. Por fim, encerramos com um trecho de incelença cantada por Esterlina, onde somos lembrados de que a morte é para todos e nós também, um dia, seremos cantados.

\section{... Que a morte chega \\ Calada e sozinha \\ Dizendo consigo: \\ Esta alma é minha \\ Não conheces os teus \\ Que contigo estão \\ Com ânsia tão grande \\ No teu coração?}

\section{CONCLUSÃO}

À guisa de conclusão, este estudo comprova o caráter de representação da cultura popular na literatura de Arriete Vilela, aqui evidenciado sobre as impressões de nossa contato com o conto "O enterro das bonecas". 
Ano 6, Vol. 6 (2), no 2. 2021, julho/dezembro de 2021.

https://doi.org/10.48179/revext.v6i2.299

Também percebeu-se a forte presença da oralidade em contrapartida a uma personagem inicialmente sem voz e que, em seus aparentes devaneios, recorria ao passado como fonte de rememoração.

A beleza dos costumes e crenças sertanejas é apresentada de maneira singular, de forma que conseguimos nos envolver com a ritualística empreendida por Esterlina e passamos a comungar com ela, a partir das sensações que nos são evocadas na leitura da obra..

Percebemos a presença do universo mítico, poético e religioso a partir dos cantos fúnebres, chamados excelências ou incelenças. Esses, concluímos serem resultado de uma relação de performance para com a morte e reflexo da identidade das comunidades do nordeste, lidos na relação dos homens dessa terra com a sua própria cultura.

Em último lugar, salientamos a importância da obra arrieteana por recolher tais práticas da oralidade e registrá-las, para que não caiam em esquecimento, assim tornando sua produção literária de alto valor histórico e nos brindado com uma estética inconfundível.

\section{REFERÊNCIAS}

GEERTZ, Clifford. A interpretação das culturas. 1ª ed. Rio de Janeiro: LTC, 2008.

HALL, Stuart. Quem precisa da identidade? In. SILVA, Tomaz. T. Identidade e diferença: a perspectiva dos estudos culturais. Petrópolis: Vozes, 2008.

VILELA, Arriete. Maria Flor etc. Maceió: Grafmarques, 2002

ZUMTHOR, Paul. Performance, recepção, leitura. Trad. Jerusa Pires Ferreira e Suely Fenerich. $2^{\text {a }}$ ed. São Paulo: Cosac Naify, 2007. 